\title{
Impact of a dementia-friendly program on detection and management of patients with cognitive impairment and delirium in acute-care hospital units: a non-equivalent control group design
}

Nina Weldingh ( $\sim$ Nina.mickelson.weldingh@ahus.no)

Department of Research Support Service, Division of Research and Innovation, Akershus University Hospital

Marte Mellingsæter

Department of Geriatric Medicine, Akershus University Hospital

\section{Bendik Hegna}

Department of Organization Developement, Akershus University Hospital

Jūratė Šaltytè Benth

Institute of Clinical Medicine, Campus Ahus, University of Oslo

\section{Gunnar Einvik}

Department of Cardiology, Division of Medicine, Akershus University Hospital

Vibeke Juliebø

Department of Cardiology, Division of Medicine, Akershus University Hospital

\section{Bente Thommessen}

Department of Neurology, Division of Medicine, Akershus University Hospital

\section{Marit Kirkevold}

Faculty of Health Sciences, Department of Nursing and Health Promotion

\section{Research Article}

Keywords: Cognitive impairment, Delirium, Dementia-friendly hospital, Delirium screening, Delirium prevention, Delirium treatment measures, Delirium detection, Implementation

Posted Date: February 26th, 2021

DOI: https://doi.org/10.21203/rs.3.rs-206980/v1

License: (c) (i) This work is licensed under a Creative Commons Attribution 4.0 International License. Read Full License 


\section{Abstract \\ Background}

Frail older persons with cognitive impairment $(\mathrm{Cl})$ are at special risk of experiencing delirium during acute hospitalisation.

The purpose of this study was to investigate whether a dementia-friendly hospital program contributes to improved detection and management of patients with $\mathrm{Cl}$ and risk of delirium at an acute-care hospital in Norway.

Furthermore, we aimed to explore whether the program affected the prevalence of delirium, pharmacological treatment, 30-day re-hospitalisation, 30-day mortality and institutionalisation afterwards.

\section{Methods}

This study had a non-equivalent control group design and a historical control group. It was conducted at two different medical wards at a large acute-care hospital in Norway from September 2018 to December 2019. A total of 423 acute hospitalised patients 75 years of age or older were included in the study. Delirium screening and cognitive tests were recorded by research staff with the Four Assessment Test (4AT) and the Confusion Assessment Measure (CAM), while demographic and medical information was recorded from patient journals.

\section{Results}

Implementation of the dementia-friendly hospital program did not show any significant effect on the identification of patients with $\mathrm{Cl}$. However, the proportion of the patients with $\mathrm{Cl}$ who received preventive measures increased by $32.2 \%$ $(P<.001)$, compared to the control group. The share of patients screened with 4AT within 24 hours increased from $0-$ $35.5 \%(P<.001)$. Furthermore, the number of patients with $\mathrm{Cl}$ who were prescribed antipsychotic/hypnotic medications was reduced by $24.5 \%(P<.001)$. There were no differences in delirium, 30-day readmission or 30-day mortality.

\section{Conclusions}

Implementation of a model for early screening and multifactorial nonpharmacological interventions for patients with $\mathrm{Cl}$ and delirium using quality improvement methodology may improve management of this patient group, increase staff awareness of family involvement, and reduce prescriptions of antipsychotics, hypnotics and sedatives.

\section{Trial registration:}

The protocol of this study was retrospectively registered in the ClinicalTrials.gov Protocol Registration and Results System with the registration number: NCT04737733 and date of registration: 03/02/2021.

\section{Background}

The number of elderly people in the world is increasing, with estimates of a doubled proportion of persons over 60 years between 2015 and 2050 (1). Comorbidity, as well as impaired physical and cognitive function, is more common in older age, and the patients require hospitalisations more frequently. One third of older patients presenting in the hospital emergency department have some type of cognitive impairment $(\mathrm{Cl})(2,3)$. Dementia and $\mathrm{Cl}$ are risk factors 
for developing delirium during their hospital stays (4-6), and the delirium prevalence in general medical wards is estimated to be 18-35\% (5). Delirium during acute hospital stays is associated with hospital falls, increased length of stay, admission to long-term care and increased mortality $(5,7,8)$. Delirium also increases the risk of developing dementia and worsening pre-existing $\mathrm{Cl}(9-11)$. Since the risk of delirium increases with the number of risk factors present, a multi-component approach targeting the patient's risk factors is probably the most effective strategy for reducing the risk of delirium (12). Nonpharmacological approaches focusing on risk factors, such as visual and hearing impairment, dehydration, immobility and sleep deprivation, are documented as effective for delirium prevention and are also recommended as treatment of delirium (7). However, despite the frequently occurring conditions and the evidence of delirium as preventable (13), screening of $\mathrm{Cl}$ and delirium is rarely implemented as routine practice in hospital wards, and in about $75 \%$ of the cases, delirium is not detected (13). Effective preventive approaches are implemented in the National Institute for Health and Care Excellence Guidelines (NICE) (14), the Hospital Elder Life Program (HELP) (15) and the Acute Care for Elders (ACE) strategy (16). However, such effective interventions and preventive strategies have often included additional staff and volunteers (17-20) or specialized geriatric wards or consultations $(7,21)$. Due to differences in the organization of health care, models may not be directly transferable to Norwegian hospital wards. Furthermore, the length of hospital stay is decreasing in several European countries (22). The field needs programs that are adapted and tested in the routine practice of the current health service's organisation and with shorter hospital stays. Therefore, a dementia-friendly hospital program was designed to improve the detection, routine care and management of patients with $\mathrm{Cl}$ and the risk of delirium in acute medical wards. This multi-component intervention program included implementation of an educational program for healthcare professionals, systematic screening of $\mathrm{Cl}$, and preventive and treatment measures to reduce the incidence of delirium. The program was also designed to raise staff awareness of delirium in the hospital.

The primary aim of the study was to explore whether this dementia-friendly program improves the detection of patients with $\mathrm{Cl}$ and/or delirium and the initiation of preventive and treatment measures for these patients. Secondary aims were to assess the effects of the program on delirium screening within the first 24 hours of admission, delirium incidence, length of hospital stay, 30-day re-hospitalisation, 30-day mortality, initiation of antipsychotic or hypnotic medications during the hospital stay and admission to a higher level of care in the primary health service after discharge.

\section{Methods}

\section{Study design}

This study, with a non-equivalent control group design and a historical control group, was performed at two medical wards at a large acute-care hospital in Norway, with a catchment area of 600.000 inhabitants.

A medical pulmonary ward ( 27 beds) and a cardiac ward (28 beds) participated in this project. The control group received usual care, whereas the experimental group received usual care plus the dementia-friendly program.

\section{Study sample}

Patients 75 years of age or older who exhibited acute medical illness and were admitted to one of the participating wards between October 2018 and February 2019 (control group) and between September 2019 and December 2019 (experimental group), were eligible. A written informed consent was obtained at the bed wards, proxy consent from relatives was allowed for patients who lacked cognitive capacity. Exclusion criteria were assessed in consultation with the clinical staff and were critical illness, unable to communicate (whether from dysphasia, severe hearing loss, or inability to speak Norwegian) or isolated (with infections). Patients were only included once, implying that readmitted patients enrolled in a previous hospital stay were excluded. 


\section{Intervention: The dementia-friendly hospital program}

Implementing innovative models of care that change daily routine care has proven to be challenging (23-25). To develop and implement the dementia-friendly program, we therefore used the principles of the quality improvement model (26). This model includes Deming's Plan-Do-Study-Act (PDSA) method (27), which has been called a necessary strategy when implementing and evaluating the effectiveness of new models in practice (23-25).

The dementia-friendly hospital program was based on the National Institute for Health and Care Excellence (NICE) delirium guidelines (National Institute for Health and Care Excellence, 2010) and the HELP program (Inouye et al., 1999) and was reviewed for relevance by the advisory board for dementia at the National Association for Public Health (28) and the Oslo Delirium Research Group (29). The program comprised three parts, which are illustrated in Table 1: 1) Educational program for health practitioners. An educational program was developed to increase the staff's knowledge and awareness of patients with $\mathrm{Cl}$ and/or delirium and to support the implementation of the program; 2) Screening of $\mathrm{Cl}$ and delirium. For early identification of $\mathrm{Cl}$, the program included screening within 24 hours after admission to the medical wards using the Four Assessment Test (4AT); 3) Delirium risk factor modification and management. A 4AT score $>0$ was defined as potential $\mathrm{Cl}$ and risk of delirium, implying that risk factor modifications should be implemented in the patient's care plan. For those with a 4AT score $\geq 4$, the program promoted an additional delirium management plan. The interventions to prevent and manage delirium are shown in Table 1. 


\section{Table 1. The dementia-friendly hospital program}

\section{Educational program for health practitioners}

Digital educational electronic How patients with CI may experience hospital admission

course Detection of patients with CI and delirium

Delirium-prevention treatment strategy and follow-up of CI

'Nurse-champions'

Morning lecture

Pocket-sized handouts
Three local 'nurse-champions', on each ward.

30-minute lecture for the ward physicians by a geriatric specialist

Visualizing the 4AT screening tool, the multi-component preventive interventions and delirium

management suggestions

\section{Screening of cognitive impairment and delirium}

4AT screening within 24 hours after admission to the ward

\section{Interventions to prevent}

\section{delirium}

Orientation Orienting communications

Ensure patient has eyeglasses and hearing aids, if needed

Nutrition and hydration

Early recognition of dehydration and risk of malnutrition

Encouragement of oral intake of fluids and encouragement during meals

Early correction of hypovolemia and electrolyte imbalance

Elimination

Prevent obstipation (e.g. encourage regular toilet routines)

Early recognition of urinary retention (e.g. bladder scanning)

Mobilisation

Encourage daily mobilisation adapted to previous functional level

Avoid restraints and immobilising equipment if possible (e.g. Foley catheters)

Sleep hygiene

(20)

Pain management

Cognitive stimulation to reduce sleeping during the day

Assess nonverbal signs of pain

Optimize pain management, preferably with nonopioid medications

Medications review

Review the patient's medication list to reduce polypharmacy and to avoid any medications

associated with precipitating delirium (e.g. benzodiazepines, antihistamines, high dose of opioids)

Family involvement

Facilitate presence of relatives when giving important information to the patient

Facilitate presence of relatives outside visits

\section{Management of delirium}

Identify and treat underlying

causes

Search for infections, metabolic abnormalities and acute pain and treat as appropriate

Assess polypharmacy and side effects of medications 
Place patient in single room if possible

Early assessment of need for 24-hour nursing; facilitate the presence of relatives

\begin{tabular}{ll}
\hline Prevent complications & Prevent aspiration pneumonia, pressure sores, deep venous thrombosis and falls \\
\hline Pharmacological strategies & Procedure with preferred use of type and dosage of antipsychotics to manage severe agitation \\
\hline Manage sleep-wake cycle \\
\hline Family involvement & Offer conversation with patients and relatives to inform them about delirium and follow-up after the \\
\hline Cognitive assessment & delirium \\
\hline
\end{tabular}

\section{Data collection}

The data collection was performed by three research nurses trained for the study.

\section{Demographic data}

Demographic data, such as age, gender, place of residence (home, adapted housing, institution), and family/relative network were obtained upon admission to the study.

\section{Medical data}

Medical data, such as cause of admission, active medical diagnoses, medications and medical treatment, were obtained both at admission and from their electronic medical records (EMR) after discharge. Vital signs and severity of medical condition were obtained from the National Early Warning Score2 (NEWS2) (30) upon admission to the emergency unit. The NEWS2 score uses well-established vital parameters on respiratory rate, oxygen saturation, temperature, systolic blood pressure, pulse rate, and level of consciousness or new confusion to identify patients at risk of a worsening condition. NEWS2 scores range from 0-24, where a higher score indicates higher clinical risk (31). A score $>7$ indicates a high severity and requires continuous monitoring of vital parameters.

\section{Detection of cognitive impairment}

$\mathrm{Cl}$ and delirium were assessed with two different screening tools: the Four Assessment Test (4AT) and the Confusion Assessment Method (CAM).

4AT is designed for a quick initial assessment of delirium and $\mathrm{Cl}$. The 4AT instrument is validated (32-34) and consists of four variables: alertness, shortened mental assessment, attention, and acute change or fluctuating course. A score of four or more indicates delirium, while a score of 1-3 indicates $\mathrm{Cl}$ (32). The sensitivity and specificity of detecting delirium is $88 \%$ (34). The tool also allows assessment of drowsy patients and delirium superimposed on dementia $(35,36)$. 4AT was recorded by trained research nurses during the first three days after patients were admitted to the ward. This assessment was performed by discretion from the clinical staff. During intervention, 4AT scores and journal notes on cognitive impairment filled in by the clinical staff were obtained from the EMR after departure. 'Patients with $\mathrm{Cl}^{\prime}$ was defined as all patients with a diagnosis of cognitive impairment at admission or an 4AT score of 
1 or above recorded by the research nurses. 'Cl detected' was defined as an 4AT score of 1 or above documented in the journal, or EMR reporting some form of cognitive impairment during the stay'.

CAM is the most used, validated diagnostic tool for diagnosing delirium $(37,38)$. The instrument has shown a sensitivity of $94-100 \%$ and a specificity of $90-95 \%$ for detecting delirium (38). The CAM consists of two parts: part one screens for overall $\mathrm{Cl}$ and part two includes assessment of: (1) acute onset and fluctuating course; (2) inattention; (3) disorganized thinking; and (4) altered consciousness level. If all the features of (1) and (2), as well as either (3) or (4), are met, the diagnosis of delirium is likely (positive CAM) (38). In this project, CAM was used to verify delirium when a 4AT score indicated possible delirium (4AT score of $\geq 4$ ). 'Delirium detected' was defined as 'a positive CAM or delirium diagnosis registered in the EMR'.

\section{Management of patients with cognitive impairment}

For all patients with a positive 4AT $(\geq 1)$ or an identified $\mathrm{Cl}$ during their hospital stays, a thorough review of the patient's journal was conducted upon discharge to record if, in case of yes, which type of preventive or treatment measures (according to the categorical measures in the dementia-friendly hospital program, shown in Table 1.) the patients had received during their stays.

\section{Secondary outcomes}

Data on whether patients had been screened with the 4AT within 24 hours after admission were registered from the EMR upon discharge. Other secondary variables included: number of days in the hospital (number of days from admission to discharge), falls during the stay, care needs at discharge (departure to home, home with home nursing, short-term stay/rehabilitation stay or nursing home placement), 30-day readmissions from date of discharge and 30day mortality. These variables were all collected through EMR reviews after discharge. The number of medications prescribed that were not recommended for older persons was assessed from the EMR on admission and at discharge. Table 2 provides an overview of the medications that should be avoided by people at risk of delirium. Furthermore, new prescriptions of antipsychotics, sedatives or hypnotics during the hospital were also recorded from the EMR upon discharge. 
Table 2

Medications recommended avoiding for people at risk of delirium (39-42)

\begin{tabular}{|ll|}
\hline $\begin{array}{l}\text { Tricyclic } \\
\text { antidepressants }\end{array}$ & Should be avoided \\
\hline Antipsychotics & $\begin{array}{l}\text { High-dose antipsychotics should be avoided; if necessary, haloperidol, risperidone or } \\
\text { quetiapine can be used }\end{array}$ \\
\hline $\begin{array}{l}\text { First-generation } \\
\text { antihistamines }\end{array}$ & Hydroksyzin and alimemazin are not recommended \\
\hline $\begin{array}{l}\text { Corticosteroids } \\
\text { Urological drugs }\end{array}$ & $\begin{array}{l}\text { Okse caution with high-dose corticosteroids } \\
\text { Darifenacin/Fesoterodin/Mirabegron are not recommended }\end{array}$ \\
\hline Benzodiazepines & Should be avoided, but do not quit abruptly after prolonged use \\
\hline Opioids & Not recommended, but can/must sometimes be used \\
\hline Metoclopramice & Not recommended but can/must sometimes be used \\
\hline Klometiazol & Could be used to induce sleep at night \\
\hline Others & Caution with Digoxin and Lithium; monitor S-concentration \\
\hline
\end{tabular}

\section{Data management}

Study data were managed using the REDCap (Research Electronic Data Capture) tool hosted at the acute-care hospital $(43,44)$. REDCap is a secure, web-based software platform designed to support data capture for research studies, providing 1) an intuitive interface for validated data capture; 2) audit trails for tracking data manipulation and export procedures; 3) automated export procedures for seamless data downloads to common statistical packages; and 4) procedures for data integration and interoperability with external sources.

\section{Statistical analysis}

Among 212 patients in the control group, 90 were identified as 4AT-positive, whereas only nine patients (10\%) received delirium preventive and treatment measures. With the dementia-friendly hospital program, it is expected that the proportion of patients receiving preventive treatment will increase to at least $50 \%$. To show that a difference between the proportions of patients receiving preventive treatment before and after intervention is significant, according to $\chi 2-$ test at the level of $5 \%$ and with the power of $80 \%$, it is sufficient with approximately 25 patients in each group. As the data in the control group were already collected, it was decided to include equally many patients in the intervention group. In this way, precise estimates of the primary outcome will be warranted, and the sample will be sufficiently large to analyse secondary outcomes.

The demographic and clinical patient characteristics were presented as means and standard deviations (SD) for continuous variables and as frequencies and percentages for categorical variables. Categorical variables were compared between the intervention and control groups by $\chi 2$-test, while the independent sample t-test was used for comparison of continuous variables.

All tests were two-sided, and results with P-values below 0.05 were considered statistically significant. All statistical analyses were performed using SPSS v.26.

\section{Ethical considerations}


All patients were asked to consent to the use of data collected in this project. If patients lacked the capacity to consent, their relative was asked to consent. Data was managed in REDCap and stored at the local research server for sensitive data.

Ethical approval for the study was obtained from the local officer for data protection and the regional committees for medical and health research ethics (2018/666).

\section{Results Sample}

There were 212 and 211 patients in the control group and intervention group, respectively. The mean age and number of patients with pre-diagnosed dementia or $\mathrm{Cl}$ were similar in the two groups. The characteristics of the patients in each study group at the time of admission are shown in Table 3. There were more patients diagnosed with lung diseases $(66.5 \%)$ and with infections during their hospital stays $(41.0 \%)$ in the control group than in the intervention group (43.1\% and $10.9 \%$, respectively). 


\begin{tabular}{|c|c|c|}
\hline Characteristics & $\begin{array}{l}\text { Control } \\
\mathrm{N}=212\end{array}$ & $\begin{array}{l}\text { Intervention } \\
\mathrm{N}=\mathbf{2 1 1}\end{array}$ \\
\hline Age & $82.6(5.1)$ & $82.4(5.2)$ \\
\hline Mean (SD) & $114(53.8)$ & $91(43.1)$ \\
\hline Gender & 208 & 211 \\
\hline Female, n (\%) & $116(55.8)$ & $97(46.0)$ \\
\hline Marital status & $11(5.3)$ & $12(5.7)$ \\
\hline $\mathrm{N}$ & $77(37.0)$ & $92(43.6)$ \\
\hline Married/cohabitant, n (\%) & $4(1.9)$ & $10(4.7)$ \\
\hline Single, n (\%) & $209(98.6)$ & 209 (99.1) \\
\hline Widow/Widower, n (\%) & $114(53.8)$ & $122(57.8)$ \\
\hline Separated/divorced, n (\%) & $98(46.2)$ & $89(42.2)$ \\
\hline Family network & $59(27.8)$ & $57(27.0)$ \\
\hline Yes, n (\%) & 39 (18.4) & $54(25.6)$ \\
\hline Admission ward & $20(9.4)$ & $38(18.0)$ \\
\hline Cardiac, n (\%) & $4(1.9)$ & $3(1.4)$ \\
\hline Pulmonary, n (\%) & $47(22.2)$ & $61(28.9)$ \\
\hline Transferred between wards during the hospital stay & $14(6.6)$ & $14(6.6)$ \\
\hline Yes, n (\%) & $11(5.2)$ & $5(2.4)$ \\
\hline Level of health care at admission & 0 & $1(0.5)$ \\
\hline No health care services, n (\%) & $192(90.6)$ & $177(83.9)$ \\
\hline Other health care services, $\mathrm{n}(\%)$ & $141(66.5)$ & $91(43.1)$ \\
\hline Weekly home nursing care, $\mathrm{n}(\%)$ & $28(13.2)$ & $37(17.5)$ \\
\hline Daily home nursing care, n (\%) & $59(27.8)$ & $59(28.0)$ \\
\hline Long-term institutional care, $\mathrm{n}(\%)$ & $7(3.3)$ & $4(1.9)$ \\
\hline Rehabilitation/short term stay, n (\%) & $87(41.0)$ & $23(10.9)$ \\
\hline Comorbidities at admission & $12(5.7)$ & $13(6.2)$ \\
\hline No diagnosis before admission & $16(7.5)$ & $6(2.8)$ \\
\hline Heart failure, n (\%) & $161(75.9)$ & $116(55.0)$ \\
\hline Pulmonary disease, $\mathrm{n}(\%)$ & $206(97.2)$ & $209(99.1)$ \\
\hline Cancer, n (\%) & $3.9(2.9)$ & $3.3(2.7)$ \\
\hline Endocrinologic disease, n (\%) & $133(62.7)$ & $150(71.1)$ \\
\hline
\end{tabular}




\begin{tabular}{|c|c|c|}
\hline Characteristics & $\begin{array}{l}\text { Control } \\
N=212\end{array}$ & $\begin{array}{l}\text { Intervention } \\
\mathrm{N}=211\end{array}$ \\
\hline Skeletal fracture, n (\%) & $60(28.3)$ & $56(26.5)$ \\
\hline Infection, n (\%) & $19(9.0)$ & $5(2.4)$ \\
\hline \multicolumn{3}{|l|}{ Dementia/cognitive impairment, $\mathrm{n}(\%)$} \\
\hline \multicolumn{3}{|l|}{ Mental illness, n (\%) } \\
\hline \multicolumn{3}{|l|}{ Other diagnosis, n (\%) } \\
\hline \multicolumn{3}{|c|}{ Symptoms of acute functional impairment 2 weeks before admission, $\mathrm{n}(\%)$} \\
\hline \multicolumn{3}{|l|}{ NEWS at admission } \\
\hline \multicolumn{3}{|l|}{ Mean (SD) } \\
\hline \multicolumn{3}{|l|}{ Cognitive function (4AT) at admission, cat. } \\
\hline \multicolumn{3}{|l|}{ No cognitive impairment $(4 \mathrm{AT}=0), \mathrm{n}(\%)$} \\
\hline \multicolumn{3}{|l|}{ Suspicion of cognitive impairment (4AT = 1-3), n (\%) } \\
\hline Cognitive impairment or delirium (4AT $\leq 4), \mathrm{n}(\%)$ & & \\
\hline
\end{tabular}

\section{Detection and screening of $\mathrm{Cl}$}

Before the intervention, there were no patients screened with the 4AT by the clinical staff within 24 hours after admission. After implementing the dementia-friendly hospital program, the 4AT screening within 24 hours after admission was performed on $35.5 \%$ of patients $(P<.001)$. The overall 4AT screening increased from $0-46.4 \%(P$ $<.001)$. The proportion of patients with identified $\mathrm{Cl}$ was similar between the groups, $58.8 \%$ in the control group and $63.3 \%$ in the intervention group $(P=.523)$.

\section{Management of patients with cognitive impairment and delirium}

Of those patients identified with delirium or at risk of delirium in the intervention group, $77.2 \%$ had documented interventions to prevent and/or treat delirium, according to the implemented dementia-friendly program (measures and interventions categorized as in Table 1). This was a statistically significant increase of $32.2 \%(P<.001)$, compared to the control group. The number of patients with preventive measures documented in their individual care plans was $32.1 \%$ higher in the intervention group compared to the control group. Furthermore, the patients in the intervention group received measures from a broader range of preventive and treatment intervention categories (132 intervention categories) than those in the control group (52 intervention categories). Table 4. shows the distribution of the number of patients receiving the different intervention categories. The intervention category 'cooperation with and presence of relatives' had the highest increase of $28.1 \%$. 
Table 4

Documented preventive and treatment measures for patients identified with $\mathrm{Cl}$

\begin{tabular}{|llll|}
\hline Characteristics & Control & Intervention & P-value $^{1}$ \\
\hline Documented measures in patient journal & 60 & 57 & $<0.001$ \\
& $27(45.0)$ & $44(77.2)$ & \\
& & & \\
$\mathrm{N}(\%)$ & & & \\
\hline Orientation & & & \\
Nutrition and hydration & $5(8.3)$ & $14(24.6)$ \\
Elimination & $2(3.3)$ & $14(24.6)$ \\
Stabilized vital abnormalities & $3(5.0)$ & $10(17.5)$ \\
Mobilization & $1(1.7)$ & $1(1.8)$ \\
Sleep hygiene & $2(3.3)$ & $11(19.3)$ \\
Pain management & $2(3.3)$ & $12(21.1)$ \\
Family involvement & 0 & $4(7.0)$ & \\
Medications review & $2(3.3)$ & $24(42.1)$ \\
Primary nursing & $3(5.0)$ & $1(1.8)$ \\
Single room & $2(3.3)$ & $3(5.3)$ \\
Referral to cognitive assessment & $6(10.0)$ & $2(3.5)$ \\
Other follow-up related to suspicion of Cl & $12(20.0)$ & $5(8.8)$ \\
\hline 1 P-value for $\chi^{2}$-test & & $31(54.4)$ \\
\hline
\end{tabular}

\section{Use of antipsychotics, hypnotics and sedatives}

Among the patients identified with some form of $\mathrm{Cl}$, there was a tendency to decrease the use of benzodiazepines and opioids at discharge, controlled for use of corresponding medication at admission. Benzodiazepines were the most frequently used by not recommended medications (Table 2).

The number of patients with a $\mathrm{Cl}$ that received antipsychotic/hypnotic medications during their hospital stays was significantly reduced from $41.2 \%$ in the control group to $16.7 \%$ in the intervention group $(P<.001)$. Data are shown in Table 5. 
Table 5

Patients with $\mathrm{Cl}$ given antipsychotic/hypnotic medications during the hospital stay

\begin{tabular}{|llll|}
\hline Characteristics & Control & Intervention & P-value \\
\hline Patients given doses of antipsychotic/hypnotic medications & 102 & 90 & $<0.001^{1}$ \\
$\mathrm{~N}$ & $42(41.2)$ & $15(16.7)$ & \\
$\mathrm{n}(\%)$ & $20(19.6)$ & $6(6.7)$ & \\
1 medication, $\mathrm{n}(\%)$ & $6(5.9)$ & $4(4.4)$ & \\
2 medications, $\mathrm{n}(\%)$ & $11(10.8)$ & $2(2.2)$ & $0.004^{1}$ \\
3 medications, $\mathrm{n}(\%)$ & $5(4.9)$ & $3(3.3)$ & $0.007^{2}$ \\
4 medications or more, $\mathrm{n}(\%)$ & $1.1(2.3)$ & $0.4(1.0)$ & \\
Mean (SD) & & & \\
\hline 1 P-value for $\chi^{2}$-test; ${ }^{2}$ P-value for independent samples t-test & & & \\
\hline
\end{tabular}

\section{Departure to rehabilitation or nursing home}

There was no difference in institutionalisation after discharge between the control group and the intervention group. Among patients receiving home nursing care at the time of admission, there was a $16.9 \%$ increase in departure to rehabilitation or other types of short-term stay in a nursing home.

\section{Length of hospital stay, delirium, readmissions and mortality}

Length of hospital stay decreased by 0.8 days in the intervention group (5.4 days) compared to the control group (6.2 days). However, this change was not statistically significant $(P<.152)$. There were no differences in delirium, 30-day readmission or 30-day mortality.

\section{Discussion}

\section{Detection and screening of cognitive impairment}

In this study, we aimed to improve the detection and management of patients with $\mathrm{Cl}$ and delirium by implementing a dementia-friendly hospital program. Our primary aim was to improve the detection of patients with $\mathrm{Cl}$, as patients with $\mathrm{Cl}$ are at high risk of developing delirium, which is associated with several adverse outcomes. Implementation of the program improved the overall detection of patients with $\mathrm{Cl}$ only slightly and the change was not statistically significant. However, to understand the results, it is important to know that we defined all journal notes, reporting some form of cognitive impairment during the stay as ' $\mathrm{Cl}$ detected' in the control group. When a nurse had written 'patient not oriented this evening', that was scored as 'Cl detected', even if no more details or plan for follow-up were given. Thus, differences in management of the patients with $\mathrm{Cl}$ might be a better identification of implementation.

A secondary outcome was to implement early systematic screening with 4AT. The 4AT instrument was not known or used in the wards at baseline. After implementing the program, 35.5\% of patients in the intervention group were screened within 24 hours after admission. The overall screening increased from $0 \%$ in the control group to $46.4 \%$ in the intervention group. One reason why we only screened close to half of the patients could be due to problems reaching out to all the staff with information. Vacancies were covered by new staff who had not been trained to conduct the screening. In addition, during the implementation period, high workloads might have reduced the time available to 
complete the screening because the staff had to prioritize care for acutely ill patients. Thus, they might have omitted screening patients who were assumed to have normal cognitive functions.

Previous studies aimed at improving the use of 4AT screening have shown a $21-64 \%$ improvement of screenings (45-48). However, Bearn et al. (47) was the only study with a baseline screening of $0 \%$, as in our study, implying that the 4AT instrument was already known and in use by the healthcare staff in the other studies. We assume that

implementation of a new screening instrument requires more resources and commitment. Despite Bearn et al. showing an overall improvement in screenings from 0-64\% 4AT, they only included screenings of newly confused patients, and the sample size was small. In our study, we intended to screen every patient 75 years and older, which means that many of them did not show signs of $\mathrm{Cl} /$ delirium. Another explanation of the differences from our study may be the 13 weeks longer study period in the study by Bearn et al. Due to rotations in the work plan, daily changes occurred amongst the health staff. This made it challenging to reach out with training and information to all staff members. This led to a prolonged and gradual incorporation of screenings into the daily routines. It is possible that the share of patients screened would have been higher with a longer implementation and study period.

\section{Management of patients with cognitive impairment and delirium}

Implementing the dementia-friendly program in this study improved management of patients with $\mathrm{Cl}$ by $32 \%$, compared to the control group. The results also indicated that the patients with $\mathrm{Cl}$ in the intervention group received more delirium preventive measures and improved communication with the informal careers' during hospitalisation. In the control group, the medical journal notes indicated that more focus was put on referrals to further assess cognitive functions during the hospitalisations or in the community care than on preventing delirium during the hospitalisation. This may indicate that the dementia-friendly hospital program increased nurses' awareness of $\mathrm{Cl}$ as a risk factor for developing delirium and the importance of differentiating delirium from dementia. Early screenings may also have led to earlier measures and follow-up during the hospitalisations. Results from this study contribute to the literature, showing that educational programs can improve the management of patients with $\mathrm{Cl}$ and delirium (48-50). Qualitative interviews with relatives of patients with Cls emphasise the importance of building good partnerships with family careers' (51). The dementia-friendly program, including the e-learning course, may have improved the health professionals' understanding of the importance of partnerships between the health care services and families. However, further studies are needed to explore this assumption.

\section{Use of antipsychotics, hypnotics and sedatives}

Antipsychotics, hypnotics and sedatives have potentially deliriogenic effects $(41,52)$. The dementia-friendly program tested in this study showed a $24.5 \%$ reduction in prescription of antipsychotic, sedative and hypnotic medications for patients with $\mathrm{Cl}$. These results may indicate that the health personnel had more knowledge and, thus, were more careful in using these kinds of medications. The program emphasises the importance of using nonpharmacological interventions rather than drugs. These results are in line with results from previous trials exploring the effects of nonpharmacological interventions targeted at delirium risk factors $(18,53)$. Chong et al. $(53)$ explored the effects of a program based on core interventions from the HELP program and detected a lower use of antipsychotic dosages in the patients at the unit where these interventions were implemented.

\section{Departure to rehabilitation or nursing home}

Several trials have studied the effects of HELP-related models on institutionalisation, but with ambiguous results (17). Our study shows no difference in overall admissions to long-term institutions at nursing homes. However, there was an insignificant increase in departures to rehabilitation or other types of short-term stays in nursing homes for the patient group receiving home care. Institutionalisation in the literature is often described as a negative result. On the other 
hand, discharge to rehabilitation or short-term stays may indicate better patient care because the patient's need for care and/or rehabilitation has been identified. The results may also be seen in connection with another result in this study, as identification of $\mathrm{Cl}$ and improved communication with family may have better identified needs for this patient group. The results must be carefully interpreted considering the organisation of the Norwegian health system, where nursing homes often include both long-term and short-term care. Acute hospitals often lack capacity and must discharge patients as soon as their medical needs are resolved. Thus, the patients often receive short-term stays at nursing homes in anticipation of being able to return home to the same level of care as before their hospital admissions.

\section{Length of hospital stay}

The effectiveness of multi-component nonpharmacological interventions in reducing the length of hospital stays has been studied in several trials $(17,54)$. However, the results are ambiguous. In this study, the length of hospital stays showed an insignificant reduction of 0.8 days in the intervention group compared to the control group. This result is in line with the meta-analysis by Hshieh et.al. (17) on the effectiveness of the HELP program, showing an insignificant mean reduction of 0.24 days in the intervention group. The difference was not statistically significant; however, the mean length of stay for patients $\geq 75$ years in the two participating medical wards was only 4.1 days after intervention, and thus a reduction of 0.8 days may be of clinical importance.

\section{Delirium, readmissions and mortality}

No difference in the number of patients diagnosed with delirium, falls, 30-day readmissions to the hospital or 30-day mortality was found. The results differ from a meta-analysis by Hshieh et al. (17), which reports significant reductions in delirium incidences after implementation of HELP-based interventions. However, other literature suggests that effects of delirium-preventive interventions on outcomes, like readmissions and mortality rates, are ambiguous (55).

\section{Strengths and limitations}

Our study has some limitations. First, $\mathrm{Cl}$ detected in the control group is based on journal notes reporting some form of cognitive impairment, without any further descriptions or follow-up of any assumed $\mathrm{Cl}$. Delirium diagnosis was also based on reviews of the medical journal report, and these data were complicated, as delirium may not have been documented correctly or not documented at all in the EMR. Second, 4AT screening was limited to only three consecutive days in the hospital for each participant, and there was no screening by research staff on the weekends, implying that not all patients have three (consecutive) screening scores.

However, our study also has several strengths.

We used validated and established screening instruments to detect patients at risk, and the measures used in the intervention are based on well-known models and guidelines.

Additionally, by using a well-researched quality improvement model and engaging the ward in the development and implementation of the intervention, this recommended model for assessing $\mathrm{Cl}$ and delirium was incorporated as part of the routine in these wards, which may facilitate subsequent improvements beyond the project period.

\section{Implications for clinical practice}

Implementing this program has provided benefits for hospitalised older patients with $\mathrm{Cl}$ and delirium. Furthermore, health care professionals have gained valuable knowledge about how to implement new tools and measures in a challenging, busy environment. From a clinical perspective, systematic and consistent screening with subsequent assessment of whether the $\mathrm{Cl}$ detected is delirium or long-term cognitive impairment may be of more importance than

Page 15/20 
the choice of screening tool. However, given the complexity and cost associated with managing patients with delirium, the simple 4AT screening tool may help target resources more appropriately.

Further implementation of this program should focus on communication with risk patients' informal caregivers and community-based health care services on how to recognize and manage delirium, as early detection and management in the community may prevent further hospital admissions.

\section{Conclusions}

A dementia-friendly hospital program, consisting of an educational program, use of a screening tool, and preventive and treatment protocols, did not show any significant effect on the identification of patients with $\mathrm{Cl}$. However, it significantly increased the management of the patients identified with $\mathrm{Cl}$ and at risk of delirium, including reducing the prescription of antipsychotic, sedative and hypnotic medications for these patients. However, implementing such a model in acute medical wards is challenging due to the limited focus on preventive measures compared to the treatment of acute diagnoses.

\section{List Of Abbreviations}

HELP: Hospital Elder Life Program; ACE: Acute Care for Elders; NICE: National Institute for Health and Care Excellence Guidelines; Cl: Cognitive Impairment; PDSA: Plan-do-study-act circle; QI: Quality Improvement; 4AT: Four Assessment Test; CAM: Confusion Assessment Measure; Electronic Medical Records (EMR).

\section{Declarations}

\section{Ethics approval and consent to participate}

Ethical approval for the study was obtained from the local officer for data protection and the regional committees for medical and health research ethics (Case number: 2018/666) and all methods were performed in accordance with the relevant guidelines and regulations. Informed consent was obtained from all study participants in this project. In cases where patients lacked consent capacity, informed consent was obtained from their relatives. Participants could refuse (further) participation at any time.

\section{Consent for publication}

Not applicable

\section{Availability of data and materials}

The dataset generated and/or analysed during the current study is available from the corresponding author by reasonable request.

\section{Competing interests}

The authors declare that they have no competing interests in this work.

\section{Funding}

The study was funded by the National Association for Public Health (28). The funding body had no influence on the analysis or design of the manuscript. 


\section{Authors' contributions}

NMW has been the primary author and has made substantial contributions to the design, data collection, analysis and drafting of the manuscripts. MK has been the primary supervisor and has contributed substantially with intellectual feedback though the development of design, data collection and analysis. BWH and MRM have contributed substantially to the design and development of the model. MRM has also contributed with supervision of analyses. JS has made all the statistical analyses and prepared data tables. GE, VJ and BT have contributed with supervision thought the study period. All Authors reviewed the manuscript.

\section{Acknowledgements}

We would like to thank Signe Anette Nærbø Strindhaug, Linda Andresen, Helene Vestvik and Helena Tangstad Kuven for their contributions to the data collection.

\section{References}

1. World Health Organization. Ageing and health [Internet]. Geneva: WHO; 2018 [updated 5. Feb. 2018]. Available from: https://www.who.int/news-room/fact-sheets/detail/ageing-and-health.

2. Evensen S, Saltvedt I, Ranhoff AH, Myrstad M, Myrstad C, Mellingsæther M, et al. Delirium og kognitiv svikt blant eldre i norske akuttmottak. Translated Title: Delirium and cognitive impairment among elderly in the emergency departments in Norway. Tidsskrift for den Norske laegeforening: tidsskrift for praktisk medicin, ny raekke. 2019;2019;139.

3. Bickel H, Hendlmeier I, Heßler JB, Junge MN, Leonhardt-Achilles S, Weber J, et al. The Prevalence of Dementia and Cognitive Impairment in Hospitals. Deutsches Arzteblatt international. 2018;115(44):733-40.

4. Juliebø V, Krogseth M, Neerland BE, Watne LO, Wyller TB. Delirium-a common condition associated with negative outcome in the elderly. Norsk epidemiologi. 2012;22(2).

5. Inouye SK, Westendorp RG, Saczynski JS. Delirium in elderly people. Lancet. 2014;383(9920):911-22.

6. Kolanowski A. Delirium in people living with dementia: a call for global solutions. Aging \& mental health. 2018;22(4):444-6.

7. Oh ES, Fong TG, Hshieh TT, Inouye SK. Delirium in older persons: advances in diagnosis and treatment. Jama. 2017;318(12):1161-74.

8. Reynish EL, Hapca SM, De Souza N, Cvoro V, Donnan PT, Guthrie B. Epidemiology and outcomes of people with dementia, delirium, and unspecified cognitive impairment in the general hospital: prospective cohort study of 10,014 admissions. BMC Med. 2017;15(1):140-.

9. Davis DHJ, Muniz Terrera G, Keage H, Rahkonen T, Oinas M, Matthews FE, et al. Delirium is a strong risk factor for dementia in the oldest-old: a population-based cohort study. Brain. 2012;135(9):2809-16.

10. Krogseth M, Watne LO, Juliebo V, Skovlund E, Engedal K, Frihagen F, et al. Delirium is a risk factor for further cognitive decline in cognitively impaired hip fracture patients. Archives of gerontology and geriatrics. 2016;64:3844.

11. Krogseth $M$, Wyller TB, Engedal $K$, Juliebo V. Delirium is an important predictor of incident dementia among elderly hip fracture patients. Dement Geriatr Cogn Disord. 2011;31(1):63-70.

12. Inouye SK. Delirium-A Framework to Improve Acute Care for Older Persons. Journal of the American Geriatrics Society. 2018;66(3):446-51. 
13. Flaherty JH, Yue J, Rudolph JL. Dissecting Delirium: Phenotypes, Consequences, Screening, Diagnosis, Prevention, Treatment, and Program Implementation. Clinics in geriatric medicine. 2017;33(3):393-413.

14. National Institute for Health and Care Excellence. Delirium: prevention, diagnosis and management [Internet]. London: NICE; 2010 [updated 2019 Mar 14]. Available from: https://www.nice.org.uk/guidance/cg103.

15. Inouye SK. Predisposing and precipitating factors for delirium in hospitalized older patients. Dement Geriatr Cogn Disord. 1999;10(5):393-400.

16. Sinha SK, Bennett J, Ramsden R, Bon J, Chalk T. Delivering improved patient and system outcomes for hospitalized older adults through an Acute Care for Elders Strategy. Healthcare management forum. 2018;31(4):126-32.

17. Hshieh TT, Yang T, Gartaganis SL, Yue J, Inouye SK. Hospital Elder Life Program: Systematic Review and Metaanalysis of Effectiveness. The American journal of geriatric psychiatry: official journal of the American Association for Geriatric Psychiatry. 2018;26(10):1015-33.

18. Gorski S, Piotrowicz K, Rewiuk K, Halicka M, Kalwak W, Rybak P, et al. Nonpharmacological Interventions Targeted at Delirium Risk Factors, Delivered by Trained Volunteers (Medical and Psychology Students), Reduced Need for Antipsychotic Medications and the Length of Hospital Stay in Aged Patients Admitted to an Acute Internal Medicine Ward: Pilot Study. Biomed Res Int. 2017;2017:1297164.

19. Godfrey M, Smith J, Green J, Cheater F, Inouye SK, Young JB. Developing and implementing an integrated delirium prevention system of care: a theory driven, participatory research study. BMC health services research. 2013;13:341-.

20. Verma J, O'Connor P, Hodge J, Abrams H, Bennett J, Sinha S. Healthcare for the Aging Citizen and the Aging Citizen for Healthcare: Involving Patient Advisors in Elder-Friendly Care Improvement. Healthcare quarterly (Toronto, Ont). 2017;20(1):14-7.

21. Fox MT, Persaud M, Maimets I, O'Brien K, Brooks D, Tregunno D, et al. Effectiveness of acute geriatric unit care using acute care for elders components: a systematic review and meta-analysis. Journal of the American Geriatrics Society. 2012;60(12):2237-45.

22. Hospital discharges and length of stay statistics Eurostat Statistic explained2020 [updated 16.Sept. 2020; cited 2020 25.Sept.]. Available from: https://ec.europa.eu/eurostat/statistics-

explained/index.php/Hospital_discharges_and_length_of_stay_statistics\#Average_length_of_hospital_stay_for_inpatients.

23. Choudry MI, Stewart K, Woodhead T. The Royal College of Physician's Quality Improvement Hub - how can it help physicians to improve patient care? Future Hosp J. 2016;3(3):211-6.

24. Knudsen SV, Laursen HVB, Johnsen SP, Bartels PD, Ehlers LH, Mainz J. Can quality improvement improve the quality of care? A systematic review of reported effects and methodological rigor in plan-do-study-act projects. BMC health services research. 2019;19(1):683.

25. Taylor MJ, McNicholas C, Nicolay C, Darzi A, Bell D, Reed JE. Systematic review of the application of the plan-dostudy-act method to improve quality in healthcare. BMJ quality \& safety. 2014;23(4):290-8.

26. Langley G, Nolan K, Nolan T, Norman C, Provost L. A model for improvement. The improvement guide: a practical approach to enhancing organization performance San Francisco: Jossey Bass. 1996:3-11.

27. Moen R. Foundation and History of the PDSA Cycle: Assoc Process Improv; 2009 [cited 2020 25. Aug]. Available from: https://deming.org/wp-content/uploads/2020/06/PDSA_History_Ron_Moen.pdf.

28. National Association of Public Health. [cited 2020 25. Aug.]. Available from: https://nasjonalforeningen.no/. 
29. Oslo Delirium Research Group. University of Oslo; [cited 2020 25. Aug]. Available from:

https://www.med.uio.no/klinmed/english/research/groups/delirium/.

30. Royal College of Physicians. National Early Warning Score (NEWS) 2: Standardising the assessment of acuteillness severity in the NHS. Updated report of a working party. London RCP; 2017.

31. McGinley A, Pearse RM. A national early warning score for acutely ill patients. BMJ: British Medical Journal. 2012;345:e5310.

32. Bellelli G, Morandi A, Davis DH, Mazzola P, Turco R, Gentile S, et al. Validation of the 4AT, a new instrument for rapid delirium screening: a study in 234 hospitalised older people. Age and ageing. 2014;43(4):496-502.

33. Berg GV, Watne LO, Gjevjon ER. Ny screening gir sikrere diagnose. Bruk av screeninginstrumentet 4A T kan forbedre diagnosti seringen av akutt delirium. Sykepleien. 2016;104:52-3.

34. Tieges Z, Maclullich AMJ, Anand A, Brookes C, Cassarino M, O'Connor M, et al. Diagnostic accuracy of the 4AT for delirium detection in older adults: systematic review and meta-analysis. Age and ageing. 2020.

35. De J, Wand AP. Delirium Screening: A Systematic Review of Delirium Screening Tools in Hospitalized Patients. The Gerontologist. 2015;55(6):1079-99.

36. Shenkin SD, Fox C, Godfrey M, Siddiqi N, Goodacre S, Young J, et al. Delirium detection in older acute medical inpatients: a multicentre prospective comparative diagnostic test accuracy study of the 4AT and the confusion assessment method. BMC Med. 2019;17(1):138-.

37. Inouye SK, van Dyck CH, Alessi CA, Balkin S, Siegal AP, Horwitz RI. Clarifying confusion: the confusion assessment method. A new method for detection of delirium. Annals of internal medicine. 1990;113(12):941-8.

38. Mariz J, Costa Castanho T, Teixeira J, Sousa N, Correia Santos N. Delirium diagnostic and screening instruments in the emergency department: an up-to-date systematic review. Geriatrics. 2016;1(3):22.

39. Francis J. Delirium and acute confusional states:Prevention,treatment, and prognosis. In: Aminoff MJ, Schmader KE, Wilterdink JL, editors. UpToDate. Hentet 25. februar 2019 fra https://uptodate.com/contents/delirium-andacute-confusional-states-prevention-and-prognosis2019.

40. Clegg A, Young JB. Which medications to avoid in people at risk of delirium: a systematic review. Age and ageing. 2011;40(1):23-9.

41. Moore AR, O'Keeffe ST. Drug-induced cognitive impairment in the elderly. Drugs \& aging. 1999;15(1):15-28.

42. Shinohara M, Yamada M. [Drug-induced Cognitive Impairment]. Brain and nerve = Shinkei kenkyu no shinpo. 2016;68(4):421-8.

43. Harris PA, Taylor R, Minor BL, Elliott V, Fernandez M, O'Neal L, et al. The REDCap consortium: Building an international community of software platform partners. Journal of biomedical informatics. 2019;95:103208.

44. Harris PA, Taylor R, Thielke R, Payne J, Gonzalez N, Conde JG. Research electronic data capture (REDCap)--a metadata-driven methodology and workflow process for providing translational research informatics support. Journal of biomedical informatics. 2009;42(2):377-81.

45. Dormandy L, Mufti S, Higgins E, Bailey C, Dixon M. Shifting the focus: A QI project to improve the management of delirium in patients with hip fracture. Future healthcare journal. 2019;6(3):215-9.

46. Vardy E, Collins N, Grover U, Thompson R, Bagnall A, Clarke G, et al. Use of a digital delirium pathway and quality improvement to improve delirium detection in the emergency department and outcomes in an acute hospital. Age and ageing. 2020;49(4):672-8.

47. Bearn A, Lea W, Kusznir J. Improving the identification of patients with delirium using the 4AT assessment. Nursing older people. 2018;30(7):18-27. 
48. Bauernfreund $Y$, Butler M, Ragavan S, Sampson EL. TIME to think about delirium: improving detection and management on the acute medical unit. BMJ open quality. 2018;7(3):e000200.

49. Palmer JL, Lach HW, McGillick J, Murphy-White M, Carroll MB, Armstrong JL. The Dementia Friendly Hospital Initiative education program for acute care nurses and staff. Journal of continuing education in nursing. 2014;45(9):416-24.

50. Sampson EL, Vickerstaff V, Lietz S, Orrell M. Improving the care of people with dementia in general hospitals: evaluation of a whole-system train-the-trainer model. International psychogeriatrics. 2017;29(4):605-14.

51. Häikiö K, Sagbakken M, Rugkåsa J. Family carers' involvement strategies in response to sub-optimal health services to older adults living with dementia - a qualitative study. BMC geriatrics. 2020;20(1):290.

52. Hipp DM, Ely EW. Pharmacological and nonpharmacological management of delirium in critically ill patients. Neurotherapeutics. 2012;9(1):158-75.

53. Chong MS, Chan M, Tay L, Ding YY. Outcomes of an innovative model of acute delirium care: the Geriatric Monitoring Unit (GMU). Clinical interventions in aging. 2014;9:603-12.

54. Hshieh TT, Yue J, Oh E, Puelle M, Dowal S, Travison T, et al. Effectiveness of multicomponent nonpharmacological delirium interventions: a meta-analysis. JAMA internal medicine. 2015;175(4):512-20.

55. MacLullich AMJ, Shenkin SD. Delirium research, education and practice. Age and ageing. 2019;48(5):619-23. 